\title{
Branding no processo eleitoral: Leitura Semiótica do Texto Televisivo da Campanha Eleitoral para Prefeito da Cidade de São Paulo
}

Branding in the electoral campaign: Semiotic analysis of a televisive text for the electoral campaign to the mayor of São Paulo City

SCHMIDT SALVADOR, Marcos Vinícios; Bel.; Universidade do Estado de Santa Catarina contato@marcossalvador.com

SCOZ, Murilo; Dr.; Universidade do Estado de Santa Catarina

muriloscoz@gmail.com

N. V. DOS SANTOS, Flávio Anthero; Dr.; Universidade do Estado de Santa Catarina

flavioanvs@hotmail.com

\section{Resumo}

Este estudo tem como escopo a análise semiótica de uma peça gráfica televisiva, ligada a campanha eleitoral de 2016. Veiculado pela coligação Acelera SP, do candidato João Dória, o texto audiovisual tratou da construção da identidade do candidato, o que pressupõe uma abordagem análoga aos processos de branding adotados no campo do design. Assim, propôs-se a análise do percurso gerativo de sentido, conforme proposição da Semiótica Greimasiana, em busca da identificação das estratégias discursivas e dos atributos semânticos adotados pelo enunciador na construção de uma imagem valorativa do candidato. O método de leitura segundo patamares articulados possibilitou desvelar diferentes sentidos presentes no texto e a reafirmação de aspectos identitários de meritocracia e de esforço laboral para a construção do simulacro do candidato. Sugerem-se novas análises que aprofundem tal discussão a partir da perspectiva semiótica, com o intuito de explicitar os processos de construção das identidades políticas nos períodos eleitorais.

Palavras Chave: Semiótica Discursiva; Campanha eleitoral; Sincretismo.

\section{Abstract}

This study is aimed at the semiotic analysis of a television graphics, linked to the 2016 electoral campaign. The audio-visual text of the Acelara SP's candidate João Dória dealt with the construction of the candidate's identity, which presupposes an analogous approach to the branding processes adopted in the field of design. Thus, it was proposed the analysis of the meaning generative path, as proposed by the Greimasian Semiotics, in search of the identification of the discursive strategies and the semantic attributes adopted by the enunciator in the construction of an image of the candidate. The method of reading according to articulated levels allowed to unveil different senses present in the text and the reaffirmation of identity aspects of meritocracy and labor effort for the construction of the simulacrum of the candidate. We suggest new analyzes that deepen this discussion from the semiotic perspective. 
Keywords: Discursive-Semiotics; Electoral Campaign; Syncretism.

\section{Apresentação}

Neste estudo, busca-se fazer a leitura de uma propaganda eleitoral para a televisão da candidatura de João Dória, com a finalidade de identificar quais traços identitários o filme atribui ao candidato por meio da aplicação de conceitos vindos da Semiótica Discursiva, especificamente o Percurso gerativo de sentido.

O texto ${ }^{1}$ estudado se chama "João Dória - Trabalhador", tendo sido veiculado durante o período da campanha eleitoral municipal brasileira do ano de 2016. João Dória foi candidato a prefeito da cidade de São Paulo pela coligação Acelera SP (PSDB / PPS / PV / PSB / DEM / PMB / PHS / PP / PSL / PT do B / PRP / PTC / PTN), sendo eleito para o referido mandato. O comercial é uma inserção de 30 segundos que foi veiculado na mídia televisiva aberta, ficando disponível para visualização no site youtube pelo canal João Doria News ${ }^{2}$.

Por ser uma inserção televisiva em rede aberta, o texto, a partir de agora chamado de texto televisivo, possui caráter sincrético, manifestando-se por meio de mais de uma forma de linguagem. A esse respeito, Pietroforte esclarece que "Quando um texto manifesta mais de uma semiótica em seu plano de expressão, trata-se de uma semiótica sincrética." (Pietroforte, 2016). Portanto, a natureza semiótica sincrética do texto televisivo é assim estabelecida por haver semiótica verbal , além de elementos ligados à narrativa visual própria do audiovisual.

A análise desse texto televisivo foi feita por meio da execução do vídeo no canal do youtube. Portanto, podem ter ocorridas possíveis variações ocasionadas por diferentes calibragens de monitores que influenciam na aparência da imagem ou configurações de reproduções de qualidade de som que podem influenciar a percepção do áudio.

\footnotetext{
${ }^{1}$ Texto no presente estudo se refere a "um todo de sentido" de acordo com a Semiótica Discursiva que "dá

${ }^{2}$ https://www.youtube.com/watch?v=cqYaXrmEK_M
} 


\section{Artigo Completo}

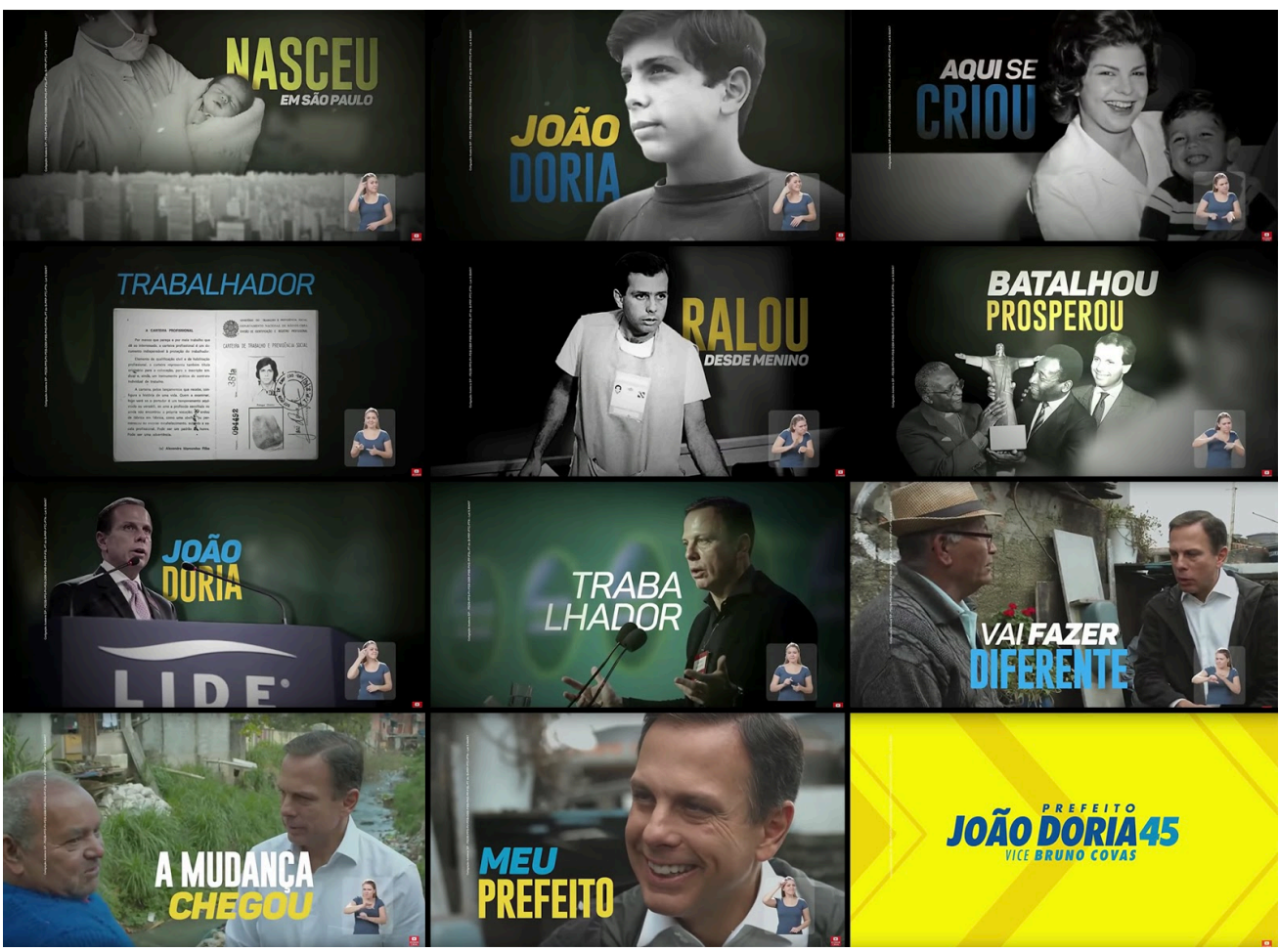

Figura 1 - Sequência de imagens estáticas presentes no texto televisivo estudado.

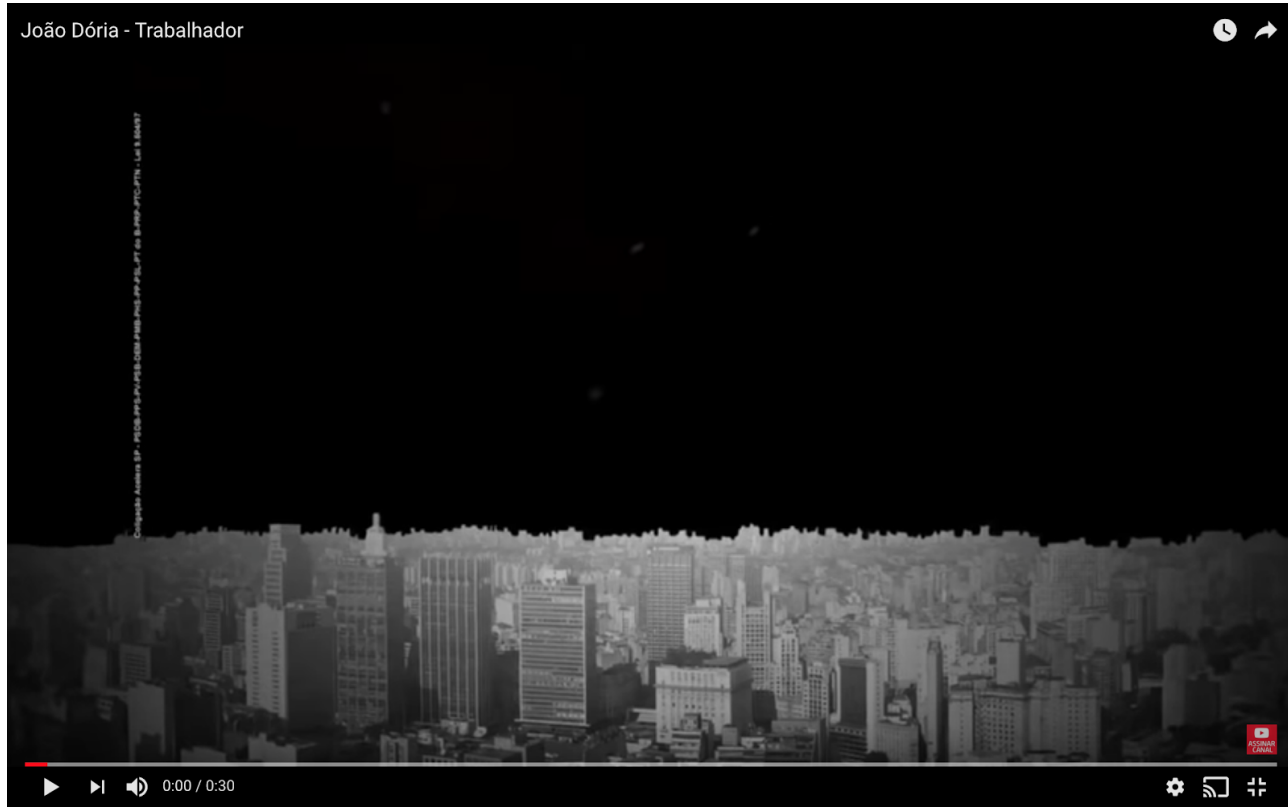

Figura 2 - Imagem estática do texto televisivo no canal do youtube João Doria News

Metodologicamente, destaca-se que a abordagem aqui desenvolvida se caracteriza pela leitura dos elementos textuais, em busca das estratégias discursivas empregadas pelo candidato. Nesta perspectiva, não são estudadas questões ligadas ao processo eleitoral, dado o caráter semiótico da discussão proposta. Para analisar política-eleitoralmente o texto televisivo, seriam necessárias muitas informações a respeito do candidato, da candidatura e do contexto eleitoral. 
Entretanto, para uma análise semiótica do texto não é necessário "conhecer a história e o contexto do autor da imagem, pois os dados indicativos desses e de outros conteúdos estão no próprio texto imagético" (Ramalho e Oliveira, 2006)

\section{Percurso gerativo de sentido}

Fiorin (2013) define o percurso gerativo de sentido por meio da caracterização da sua proposta metodológica. A conceitualização desse método de análise semiótica é feita por uma sucessão de patamares que mostra como se produz e se interpreta o sentido. Esse método de análise semiótico permite ler um texto com mais eficácia (Fiorin, 2013). A partir de agora, chamaremos esses patamares de "níveis" classificados por Fiorin (2013) da seguinte forma: níveis discursivo, narrativo e fundamental. Segundo tal proposta, os níveis orientam a leitura de um texto em um processo que vai do mais simples ao mais complexo.

\subsection{Plano da expressão}

O plano da expressão refere-se à plasticidade da imagem, com os elementos que são perceptíveis ao olhar como a cor, textura, formas, planos, linhos e materiais utilizados e também, no caso aqui estudado, às características estéticas como som como volume, ritmo e etc. O plano da expressão, então, refere-se a tudo que é possível ser percebido por um dos 5 sentidos humanos, portanto ele é constituído pelos elementos constitutivos e pelos procedimentos relacionais. A linguagem do texto estudado é a televisiva que possui entre as suas características a superficialidade, clareza e rapidez da mensagem.

[...] não se controla a comunicação audiovisual se não se conhecerem os mecanismos emocionais e inconscientes a partir dos quais ele atua [...] o analfabetismo audiovisual é mais perigoso que o verbal. $\mathrm{O}$ analfabeto verbal é consciente de sua limitação. Não poderá ter acesso à informação escrita, mas tampouco poderá ser manipulado por ela. $\mathrm{O}$ analfabeto audiovisual, no entanto, será presa fácil da manipulação audiovisual, porque terá acesso às mensagens sem capacidade de análise e, ao mesmo tempo, sem uma atitude de defesa, de controle. (FÉRRES, 1998, p.273)

O texto televisivo analisado possui quase em sua totalidade imagens figurativas sobre um fundo de tela preto. Ele possui formato possui formato widescreen. Ao decorrer da sua execução, as imagens figurativas que na primeira metade do vídeo possuem a paleta de cores em escala de cinzas, vão ganhando saturação. Palavras são colocadas na tela em cores que contrastam com as imagens apresentadas. Uma música cantada acompanha as imagens que possuem transições em formato de animação.

\subsection{Nível discursivo}

O nível discursivo é caracterizado por Fiorin (2013) como a porta de acesso a um texto semiótico. É o nível que concretiza o nível narrativo. É considerado o nível mais superficial e descritivo e pode ser abordado por meio do plano do conteúdo. O plano do conteúdo é definido por Fiorin como o plano que apresenta os efeitos dos sentidos depreendidos do texto por meio do plano da expressão.

Discurso é uma unidade do plano de conteúdo, é o nível do percurso gerativo de sentido em que formas narrativas abstratas são revestidas por elementos concretos. Quando um discurso é manifestado por um plano de expressão qualquer, temos um texto. (...) Essa distinção é metodológica e decorre do fato de 
que um mesmo conteúdo pode ser expresso por diferentes planos de expressão. Vidas secas, de Graciliano Ramos, foi veiculado por um plano de expressão verbal (o romance) e por um plano de expressão pictórico, verbal, etc: (o filme). Fiorin (2013. p. 45)

\subsubsection{Plano do conteúdo}

É necessário para o entendimento desse plano a diferenciação conceitual entre tema e figura. Fiorin (1999) define os temas como termos abstratos que ajudam a classificar os elementos do mundo natural de forma organizada (beleza, inteligência e etc.) e as figuras são termos concretos, possuindo correspondentes no mundo natural (frio, vermelho, brincar, sol, cadeira e etc.). Portanto os temas são associados a conceitos abstratos, entretanto os conceitos abstratos podem ser "recobertos" por figuras, em um processo chamado figurativização, por meio de palavras que constroem um simulacro do mundo natural.

Portanto, inicialmente, tentará traçar-se relações entre os planos da expressão e as figuras que conhece-se do mundo natural e que é possível reconhecê-las. Após essa etapa, será definido o tema do texto televisivo.

Para uma melhor compreensão da análise, o texto televisivo foi dividido em três partes iguais.

Parte 1:

Os a $10 \mathrm{~s}$

A primeira imagem apresentada pelo vídeo é o do horizonte de uma cidade em preto e branco sobre um fundo preto. A imagem da cidade ocupa o terço inferior da tela. Aos poucos a imagem da cidade desfoca e uma fotografia em tons de sépia de uma mãe segurando um bebê aparece no fundo na parte superior do quadro. Enquanto essas imagens aparecem uma voz masculina afável acompanhada de uma música, que cria uma ambiência de confiança por meio da melodia suave, diz "Nasceu em São Paulo". Conforme essa voz verbaliza as sentenças, algumas palavras vão aparecendo escritas na tela em forma de animação interagindo com a sobreposição de imagens já existentes. 


\section{Artigo Completo}

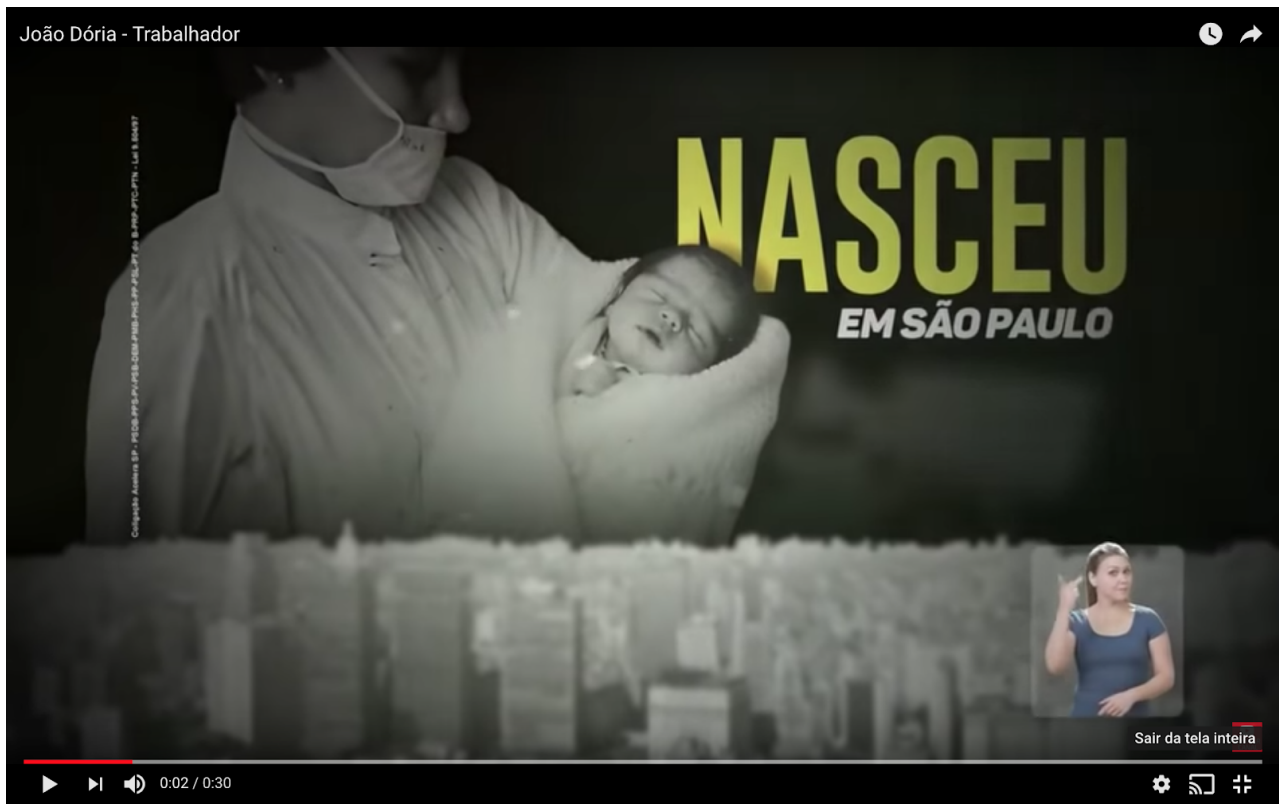

Figura 3 - Imagem estática do momento 0:02 do texto televisivo no canal do youtube João Doria News

Após esse momento, é feita uma transição por meio de um zoom que faz com que a tela fique rapidamente limpa. Aparece a imagem em preto e branco de uma senhora segurando uma criança no colo enquanto o narrador verbaliza "aqui se criou". Enquanto o narrador diz as palavras, elas vão aparecendo em forma de animação do lado da figura.

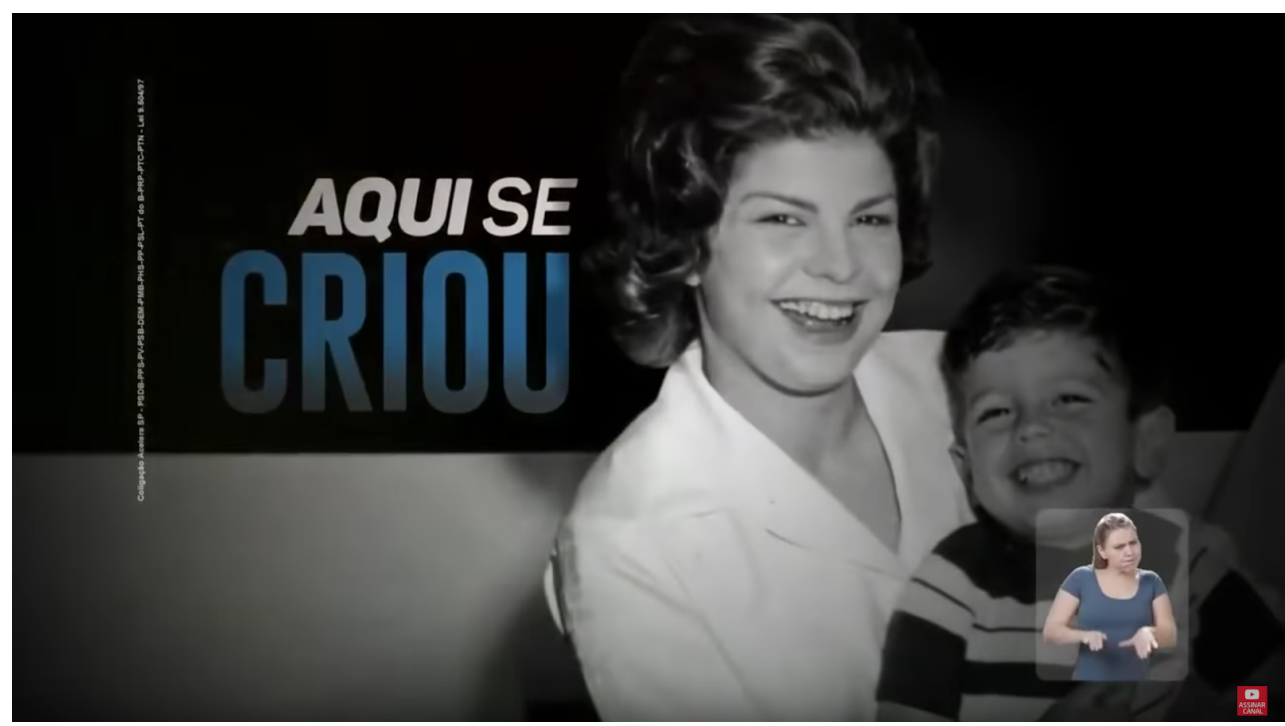

Figura 4 - Imagem estática do momento 0:05 do texto televisivo no canal do youtube João Doria News

Então, também por meio de um zoom (princípio que se repete nas transições, construindo um sentido de aprofundamento), a imagem é limpa e surge a fotografia em preto e branco de um menino acompanhado das palavras "João Dória, o que também é dito pelo narrador. Após esse momento, surge a imagem em preto e branco de uma carteira de trabalho fechada que se abre até uma página onde é possível ver anotações e uma foto de uma pessoa. Nesse momento o 
narrador fala a palavra "trabalhador" e ela aparece em cima da imagem da carteira de trabalho. Durante toda essa primeira parte do texto televisivo efeitos de luzes amarelas são sobrepostos a todo conteúdo da inserção. Por todo o texto televisivo uma mulher aparece na canto inferior direito dentro de uma caixa translúcida (embora, algumas vezes a imagem da mulher exceda o espaço que parece ser destinado a ela por meio da caixa) fazendo a tradução de tudo que está sendo dito pelo narrador para a linguagem brasileira de sinais (libras).

Parte 2:

$10 \mathrm{~s}$ a $20 \mathrm{~s}$

A segunda parte se inicia com uma imagem em preto e branco de um jovem João Dória vestindo uma espécie de avental ocupando toda a parte esquerda do ecrã. Enquanto isso, o narrador fala "ralou desde menino", e essas palavras aparecem na parte direita da tela.

Após um zoom na parte esquerda da tela, surge a imagem de João Dória, agora mais velho, vestindo um terno e camisas brancos e gravata ao lado de uma bandeira do Brasil. Enquanto o narrador diz "batalhou, prosperou", a câmera se desloca para a esquerda para revelar uma nova imagem que aparece sendo focada enquanto o narrador continua a cantar. A nova imagem é de João Dória junto com dois homens segurando uma escultura que é uma réplica da estátua do Cristo Redentor no Rio de Janeiro.

Logo após, o narrador verbaliza "João Dória" (nome que aparece ao lado da imagem) e aparece uma imagem dele discursando em uma tribuna no lado direito da tela com os dizeres LIDE embaixo. Quando o narrador canta "Trabalhador" e o texto aparece em tela, a câmera rapidamente se desloca para a direita e revela uma imagem de João Dória discursando e aparentemente falando em um microfone. Essas duas imagens dele discursando são as primeiras imagens do texto televisivo que aparecem com uma paleta de cores mais fortes e não em preto e branco ou tons de sépia.

Parte 3:

$20 \mathrm{~s}$ a $30 \mathrm{~s}$

A partir deste momento, é mostrado um vídeo em cores em que João Dória conversa com um senhor. João Dória está posicionado a direita da tela e o senhor a esquerda. Porém, o vídeo não possui áudio e o que se ouve é o narrador que continua cantando "Vai fazer diferente" enquanto essas palavras aparecem na tela. $O$ vídeo é trocado e aparece agora João Dória no lado direito conversando com uma mulher posicionada do lado esquerdo. Logo em seguida a mensagem desaparece, o vídeo é trocado por ele conversando com um senhor com um córrego como paisagem de fundo. Enquanto isso o narrador canta "a mudança chegou" (essas palavras aparecem na tela) e, novamente, após isso acontecer o vídeo é trocado. Agora João Dória conversa com uma senhora em uma feira.

Por último aparece um vídeo em tela inteira de João Dória sorrindo enquanto as palavras "meu prefeito" são cantadas e aparecem na tela. Em um instante aparece uma animação nas cores que faz com que o vídeo desapareça e surja as palavras "Prefeito João Dória 45 Vice Bruno Covas". Enquanto essa animação é apresentada, o cantor fala a palavra "trabalhador". 


\section{JOÃO D̊DORIAA 45 \\ VICE BRUNO COVAS}

$\checkmark \quad$ D 0:29/0:30

Figura 5 - Imagem estática do momento 0:29 do texto televisivo no canal do youtube João Doria News

Após analisada a figuratividade, é possível definir, então, o tema do texto televisivo. A tendência é acreditar-se que o tema deste texto televisivo é a história de vida do personagem principal. Porém algumas informações vindas do texto verbal musicado junto com elementos do texto visual oferecem uma outra análise complementar. Durante todo o texto televisivo, o cantor fala a palavra "trabalhador" e sempre que essa palavra é dita ela é apresentado através de seu vocábulo gráfico na tela. Essa repetição é um indício que o adjetivo usado interage com a história que o narrador conta. Portanto juntando o tema da história de vida com o tema do trabalho, é possível definir que o tema do texto televisivo que está sendo estudado é a evolução da vida de um homem trabalhador.

\subsection{Nível narrativo}

Após a análise das impressões mais concretas do patamar semiótico mais superficial a respeito do texto televisivo, chega a hora de analisar o nível narrativo. Fiorin (2013) explica a diferença de "narratividade" e "narração". "Narratividade" é um componente da teoria da discurso, a transformação que está situada entre dois estados sucessivos diferentes. "Narração" é a classe de discurso em que os estados e transformações estão ligados a personagens individualizadas.

A transformação sofrida pelo sujeito causada pelos objetos é observada no nível narrativo. Entretanto, não se pode achar que sujeito seja obrigatoriamente uma pessoa e o objeto um artefato. Sujeitos e objetos são papéis narrativos e podem ser representados por diferentes entidades interiores do texto. Fiorin (2013) ainda afirma que uma narrativa complexa possui a 
estrutura em sequência canônica, com quatro fases: a manipulação, a competência, a performance e a sanção.

O texto televisivo estudado é acompanhado de um narrador que fala em terceira pessoa sobre a personagem principal da história, João Dória. As informações que são trazidas por ele são complementadas por imagens, animações e palavras que são apresentadas no vídeo. Essas informações destacam os efeitos de sentido percebidos que complementam a percepção sobre o que está sendo falado e mostrado.

A sequência canônica do texto televisivo que está sendo estudado começa com a manipulação. Essa fase não é explícita na narrativa do narrador ou nas imagens mostradas. $O$ enunciador do texto pretende, por meio dele, manipular o enunciatário. Pode-se interpretar que o enunciatário é aquele que será impactado pela campanha televisa. Logo, o texto nos dá a informação que o enunciatário é o eleitor que poderá ou não votar no candidato para prefeito. $\mathrm{O}$ enunciado são as informações dadas sobre a vida do candidato que o enunciador deseja que o eleitor acredite. Fiorin (2013) define a fase de manipulação quando um sujeito semiótico atua sobre o outro para levá-lo a querer fazer alguma coisa. Portanto, o enunciador quer manipular o enunciatário, fazendo-o crer no enunciado.

A fase da competência no nível narrativo do percurso gerativo de sentido é marcada pela aquisição de um saber e/ou poder fazer que permitirá a transformação central da narrativa. Portanto, a competência a ser adquirida seria a do enunciatário ter as informações emitidas pelo enunciador. Em outras palavras, o eleitor absorver as ideias sobre o candidato que o anúncio disponibiliza.

A performance é a fase em que acontece a ação do sujeito competencializado na narrativa. Ou seja, munido do saber e/ou poder fazer adquirido na fase da competência, o sujeito opera na busca pelo seu objeto de valor. (Fiorin, 2013). Essa fase se daria quando o eleitor fosse exercer seu voto na eleição.

A última fase da narrativa é a da sanção. Fiorin (2013) define essa fase como a constatação que a performance se realizou. Essa fase também não aparece no texto televisivo. Enfim, a sanção se dará com a eleição do sujeito como prefeito da cidade de São Paulo.

Narrativamente, ainda é possível fazer uma leitura mais focada na história narrada pelo enunciador. Uma interpretação não anula a outra, e levarão para a mesma última fase da narrativa, ou seja, ambas leituras narrativas terão a mesma sanção. Portanto, nessa leitura mais focada, são apresentadas as informações que João Dória nasceu e criou-se em São Paulo. Portanto, na fase da manipulação, pode ser considerada a manipulação que o sujeito São Paulo exerce sobre o sujeito João Dória. No caso dessa leitura mais específica que está sendo analisada, São Paulo faz com que João Dória trabalhe para conquistar o objeto de valor, no caso o cargo de prefeito da cidade.

A fase da competência é percebida pelas sequências que mostram o candidato João Dória trabalhando. Desde a imagem em que ele aparece com um colete relacionado a trabalhos com uma remuneração mais barato, até trabalhos de maiores ganhos.

$\mathrm{Na}$ inserção eleitoral de João Dória, a fase da performance, é demonstrada pelas imagens (não mais estáticas como as anteriores) de João Dória fazendo campanha e conversando com 
cidadãos. Essa fase é ainda percebida mais facilmente devido a alteração da saturação das imagens que ocorre.

A última fase da narrativa, a da sanção, não aparece no texto televisivo, mas a espera pela sua realização é apontada na última imagem que aparece no texto que é o nome de João Dória juntamente com seu número para a eleição a prefeito. Portanto, a sanção, assim como na leitura mais abrangente do texto televisivo, se dará com a vitória eleitoral do candidato João Dória.

\title{
2.3 Nível fundamental
}

Ao chegar-se na análise do nível fundamental do percurso gerativo de sentido, buscam-se as categorias semânticas que baseiam a construção do texto (FIORIN, 2013). Essas categorias organizam-se nos termos de uma oposição semântica de base, que organiza os valores do texto pela qualificação semântica eufórica (positiva) ou uma disfórica (negativa) de cada elemento. semânticas:

No texto televisivo que está sendo analisado foram destacadas algumas oposições

\author{
esforço x preguiça \\ nativo $\mathrm{x}$ forasteiro \\ competente $\mathrm{x}$ incapaz \\ prosperidade $\mathrm{x}$ decadência \\ trabalho $\mathrm{x}$ ociosidade \\ diferente $\mathrm{x}$ igual \\ mudança $x$ continuação
}

meu $x$ teu

Diante das oposições semânticas encontradas, observa-se a permanência da temática do trabalho que serve de escopo para todo o texto é a de esforço x preguiça. A oposição é confirmada por outras que se alinham em cada um dos eixos, o disfórico e o eufórico. O eixo eufórico (positivo/ do esforço) é acompanhado pelos termos nativo, competente, prosperidade, trabalho, diferente, mudança e meu. Já o eixo disfórico (negativo/ da preguiça) é acompanhada de forasteiro, incapaz, decadência, ociosidade, igual, continuação e teu.

Com essas determinações, é possível construir um quadrado semiótico para organizar em termos lógicos a estrutura fundamental do texto. Barros (2013. p. 23) nos apresenta uma das funções do quadrado:

Representar as relações semânticas em sua dimensão paradigmática e propiciar-Ihes a sintagmatização pelas operações orientadas, em qualquer etapa da descrição. 0 quadrado semiótico pertence ao nível metalinguístico da semiótica. Ressalte-se, ainda, qualquer que seja a tarefa cumprida, a eficácia heurística do quadrado, enquanto modelo de previsibilidade.

Portanto, podemos organizar o quadrado semiótico fundamental do texto analisado da seguinte maneira: 


\section{ESFORÇO}

PREGUIÇA
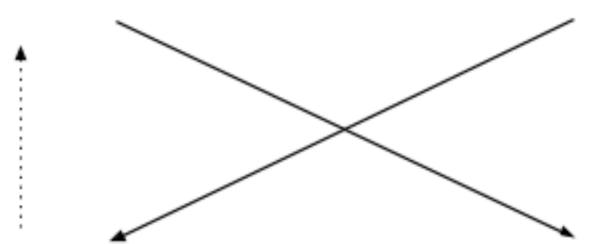

NÃO PREGUIÇA

NÃO ESFORÇO

Contraditoriedade
Contrariedade
Implicação

Figura 6 - Quadrado semiótico. Fonte: Autor

No texto estudado, por meio do quadrado semiótico, primeiro nega-se a 'preguiça', produzindo assim a sua contradição, ou seja, a 'não preguiça. Os termos 'preguiça' e 'não preguiça' não podem coexistir simultaneamente. Portanto afirma-se que por meio da 'não preguiça' obtém-se o 'esforço'. Isto é, se não é 'preguiça', é esforço. Essa relação entre esses termos é chamada de implicação.

\section{Considerações Finais}

A complexidade de análise de textos sincréticos foi percebida desde a primeira leitura do texto televisivo. As relações do plano do conteúdo com os diferentes planos da expressão constroem sentidos complexos pela articulação dos níveis do percurso gerativo de sentido com os elementos plásticos e visuais. A escolha de um texto televisivo que apresenta diferentes linguagens que se inter relacionam para formar um sentido exigiu pensar uma estratégia de análise capaz de isolar tais elementos para depois identificar sua forma de articulação. A análise de como o sentido se forma só foi possível devido a escolha de adotar uma abordagem metodológica capaz de guiar a leitura do texto, a fim de não limitar a análise aos elementos mais superficiais. Foi percebido que o texto televisivo, contrastando a sua característica eleitoral, buscou criar um simulacro do candidato João Dória. Foram ressaltados nos diversos níveis da leitura aspectos meritocráticos e laborais em sua trajetória e a possível aplicação desses traços identitários caso eleito.

A opção por um texto televisivo de uma campanha eleitoral ressaltou a maneira como são definidas as estratégias de apresentação de um candidato. Portanto, essa é uma análise apenas inicial de um texto televisivo de apenas 30 segundos de um candidato. Sugere-se para futuros estudos, uma análise sociossemiótica de como funciona uma eleição e os papéis dos sujeitos perante a formação do sentido. 


\section{Referências}

BARROS, D.L.P. Teoria do discurso: fundamentos semióticos. 3a ed. São Paulo: Humanitas/ USP, 2001.

FERRÉS, Joan. Televisão subliminar. Socializando através de comunicações despercebidas. Porto Alegre: Artmed, 1998.

FIORIN, José Luiz. Elementos de Análise do Discurso. 15. ed. São Paulo: Contexto, 2013.

FIORIN, José Luiz. Sendas e veredas da semiótica narrativa e discursiva. In: DELTA-Revista de Documentação de Estudos em Lingüística Teórica e Aplicada. São Paulo, v. 15, n. 1. 1999.

MORATO, Élisson Ferreira. Entre o verbal e o não-verbal: uma análise semiótica de textos publicitários. Revista de Letras da Universidade Tecnológica Federal do Paraná, Curitiba, v.12, n. 13, jul./dez. 2010. Disponível em: <https://periodicos.utfpr.edu.br/rl/article/viewFile/2421/1553>. Acesso em 15 jan. 2018.

PIETROFORTE, Antonio Vicente. Análise do texto visual: a construção da imagem. 2. ed. São Paulo: Contexto, 2016.

RAMALHO E OLIVEIRA, S. R. Leitura de Imagens para a Educação. Tese (Doutorado em Comunicação e Semiótica) - Programa de Pós-Graduação em Comunicação e Semiótica. São Paulo: Pontifícia Universidade Católica de São Paulo, 1998. 